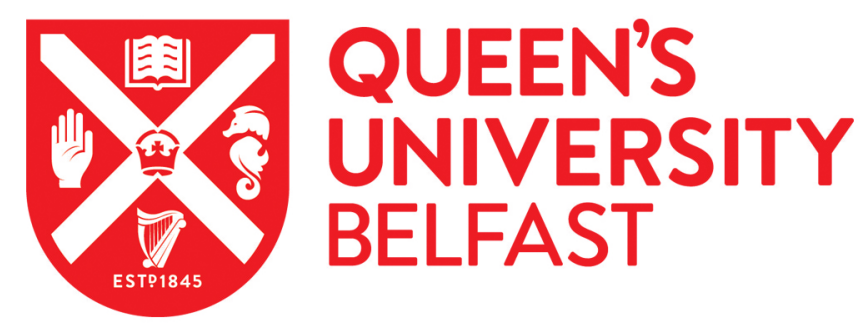

\title{
The relationship between adipokines and the onset of type 2 diabetes in middle-aged men: The PRIME study
}

Neville, C. E., Patterson, C. C., Linden, G. J., Love, K., McKinley, M. C., Kee, F., Blankenberg, S., Evans, A., Yarnell, J., \& Woodside, J. V. (2016). The relationship between adipokines and the onset of type 2 diabetes in middle-aged men: The PRIME study. Diabetes Research and Clinical Practice, 120, 24-30.

https://doi.org/10.1016/j.diabres.2016.07.010

Published in:

Diabetes Research and Clinical Practice

Document Version:

Peer reviewed version

Queen's University Belfast - Research Portal:

Link to publication record in Queen's University Belfast Research Portal

Publisher rights

(c) 2016 Elsevier Ltd. This manuscript version is made available under the CC-BY-NC-ND 4.0 license http://creativecommons.org/licenses/by$\mathrm{nc}-\mathrm{nd} / 4.0 /$ which permits distribution and reproduction for non-commercial purposes, provided the author and source are cited.

\section{General rights}

Copyright for the publications made accessible via the Queen's University Belfast Research Portal is retained by the author(s) and / or other copyright owners and it is a condition of accessing these publications that users recognise and abide by the legal requirements associated with these rights.

Take down policy

The Research Portal is Queen's institutional repository that provides access to Queen's research output. Every effort has been made to ensure that content in the Research Portal does not infringe any person's rights, or applicable UK laws. If you discover content in the Research Portal that you believe breaches copyright or violates any law, please contact openaccess@qub.ac.uk. 
The relationship between adipokines and the onset of Type 2 diabetes in middle-aged men: the PRIME study

Charlotte E. Neville ${ }^{\mathrm{a}^{*}}$, Christopher C. Patterson ${ }^{\mathrm{a}, \mathrm{b}}$, Gerard J. Linden ${ }^{\mathrm{a}}$, Karl Love ${ }^{\mathrm{a}}$, Michelle C. McKinley $^{\mathrm{a}, \mathrm{b}}$, Frank Kee ${ }^{\mathrm{a}, \mathrm{b}}$, Stefan Blankenberg ${ }^{\mathrm{c}}$, Alun Evans ${ }^{\mathrm{a}}$, John Yarnell ${ }^{\mathrm{a}}$, Jayne V. Woodside ${ }^{\mathrm{a}, \mathrm{b}}$.

\section{Affiliation:}

${ }^{a}$ Centre for Public Health, School of Medicine, Dentistry and Biomedical Sciences, Institute of Clinical Science B, Queen’s University Belfast, Belfast, BT12 6BJ, United Kingdom

${ }^{\mathrm{b}}$ Centre of Excellence for Public Health, School of Medicine, Dentistry and Biomedical Sciences, Queen’s University Belfast

${ }^{\mathrm{c}}$ Department of Medicine II, Johannes Gutenberg-University Mainz, Mainz, Germany

\section{Email addresses:}

Charlotte Neville, c.neville@qub.ac.uk

Christopher Patterson, c.patterson@qub.ac.uk

Gerard Linden, g.linden@qub.ac.uk

Karl Love, klove01@qub.ac.uk

Michelle McKinley, m.mckinley@qub.ac.uk

Frank Kee, f.kee@qub.ac.uk

Stefan Blankenberg, s.blankenberg@uke.de

Alun Evans, a.evans@qub.ac.uk

John Yarnell, j.yarnell@qub.ac.uk

Jayne Woodside, j.woodside@qub.ac.uk

* Corresponding author 


\section{Abstract:}

Aims: Epidemiological evidence suggests that adipokines may be associated with the onset of type 2 diabetes, but the evidence to date is limited and inconclusive. This study examined the association between adiponectin and leptin and the subsequent diagnosis of type 2 diabetes in a UK population based cohort of non-diabetic middle-aged men.

Methods: Baseline serum levels of leptin and adiponectin were measured in 1839 nondiabetic men aged 50-60 years who were participating in the prospective population-based PRIME study. Over a mean follow-up of 14.7 years, new cases of type 2 diabetes were determined from self-reported clinical information with subsequent validation by general practitioners.

Results: 151 participants developed type 2 diabetes during follow-up. In Cox regression models adjusted for age, men in the top third of the leptin distribution were at increased risk (hazard ratio (HR) 4.27, 95\%CI 2.67-6.83) and men in the top third of the adiponectin distribution at reduced risk (HR $0.24,95 \%$ CI $0.14-0.42$ ) relative to men in the bottom third. However, significance was lost for leptin after additional adjustment for BMI, waist to hip ratio, lifestyle factors and biological risk factors, including C-reactive protein (CRP). Further adjustment for HOMA-IR also resulted in loss of significance for adiponectin.

Conclusions: This study provides evidence that adipokines are associated with men's future type 2 diabetes risk but not independently of other risk factors.

Keywords: adiponectin, leptin, type 2 diabetes, prospective study 


\section{Introduction}

In the last decade, the prevalence of type 2 diabetes has risen dramatically throughout the world. In the UK alone, the prevalence of diagnosed cases of diabetes is 6\% [1]. Although significant advances have been made in the treatment of type 2 diabetes, much attention is now focusing on preventive measures as a means of helping to curb this epidemic. Early identification of individuals at increased risk of type 2 diabetes is a key priority for effective targeting of preventive measures.

Obesity is widely acknowledged as being a major risk factor for type 2 diabetes. Although the aetiological mechanism by which obesity increases the risk of type 2 diabetes is not fully established, it is believed that adipokines, biologically active molecules secreted by adipose tissue, may play an important pathophysiological role through their association with obesity-induced inflammation and signalling pathways. Leptin and adiponectin are two adipokines that have generated considerable research interest. Leptin is a pro-inflammatory adipokine and is closely correlated to obesity severity [2]. Adiponectin, in contrast to leptin, has anti-inflammatory and anti-atherogenic properties, and has been shown to have a positive influence on insulin sensitivity [3-5].

The evidence regarding the association between leptin and type 2 diabetes risk is conflicting, with some studies showing positive associations [6-11] and others showing no association [12-15]. Similarly, the association between adiponectin and type 2 diabetes risk has not yet been fully elucidated. A meta-analysis of 13 prospective studies published in 2009 concluded that increased levels of adiponectin were associated with a reduced risk of incident type 2 diabetes [16]. However, generalising the findings is problematic, as most of the studies included in the meta-analysis were conducted in Japanese, Pima Indian, Asian Indian or Aboriginal Canadian population groups. More recent European based prospective studies have not identified an independent association between adiponectin and type 2 diabetes [11, 17]. However, many of the prospective studies conducted to date, have had 
relatively short follow-up periods (range $3.2 \mathrm{y}-8 \mathrm{y}$ ) $[10,17,18]$, small numbers of cases of incident diabetes during follow-up $(n=82)$ [11], or have failed to fully adjust for important confounding factors, such as measures of insulin resistance [11].

Despite the increasing prevalence of type 2 diabetes in the UK, relatively few UKbased prospective studies [7, 10] have examined the association between adipokines and incident diabetes. There is also continued debate over the role of adiponectin and leptin as independent clinical markers of type 2 diabetes risk. The aim of this study was to examine the association between adiponectin and leptin and the subsequent diagnosis of type 2 diabetes in a UK population based cohort of non-diabetic middle-aged men.

\section{Methods}

\subsection{Study population}

The Prospective Epidemiological Study of Myocardial Infarction (PRIME) study is an ongoing population-based cohort study examining cardiovascular disease and associated risk factors in men from Northern Ireland. Sampling procedures and study design have been described fully elsewhere [19]. In brief, baseline data were obtained between 1991 and 1994 from 2745 men aged 50 - 60 y. Participants were recruited from industry, the civil service and general medical practices and represented approximately $5 \%$ of the male population of the greater Belfast area. The sampling framework was designed so that participants would broadly match the social class structure of the background population [19]. Written consent was obtained from all participants at baseline and ethical approval was obtained from the Research Ethics Committee of the Faculty of Medicine, Queen’s University Belfast.

\subsection{Baseline data collection}

Standardised self-report questionnaires were used to assess demographic and socioeconomic background including medical history, occupation, dietary habits, smoking and drinking 
habits and physical activity. Physical activity was based on the average weekly net energy expenditure from physical activity, expressed in metabolic equivalents (MET) hour/week [20]. Smoking status was divided into current, former or never smoked. Socio-economic status was based on two measures: fifths of deprivation of the geographical area of the home address based on the Northern Ireland Multiple Deprivation Measure 2001 (www.nisra.gov.uk/deprivation/nimdm_2001.htm) and a composite score of material conditions in the household based on three proxy indicators (the type of living accommodation (rented or owned/mortgage), the number of cars/vans/motorcycles in the household and the number of baths and/or showers and toilets in the home) [20].

A physical examination was carried out to obtain anthropometric measurements including body weight (to the nearest 200g), height (to the nearest $\mathrm{cm}$ ) and waist and hip circumference (to the nearest $0.5 \mathrm{~cm})$. Body mass index (BMI) was computed as weight/height ${ }^{2}\left(\mathrm{~kg} / \mathrm{m}^{2}\right)$. Both waist:hip ratio (WHR) and BMI have previously been shown to be strong predictors of type 2 diabetes [21, 22]. Systolic and diastolic blood pressure was the average of two measurements in the sitting position using an automatic sphygmomanometer (Spengler SP9).

\subsection{Biological measurements}

A fasting blood sample was collected and processed within 4 hours with aliquots frozen at $80^{\circ} \mathrm{C}$ until analysis. Blood samples were analysed for concentrations of leptin, adiponectin, lipids, glucose, insulin and CRP. Circulating concentrations of adiponectin and leptin were measured in plasma and serum respectively using an Elisa (R\&D Systems, Billerica, MA, USA). For quality control purposes, R\&D assay internal standards and laboratory internal plasma and serum quality controls were used within each 96-well plate. Serum levels of CRP were measured using a Latex immunoassay CRP16 (Abbott, Architect c8000). The intraassay CV for adiponectin, leptin and CRP was 4.5\%, 5.4\% and 0.9\%, respectively, while the 
inter-assay CV was $16.7 \%, 8.9 \%$ and $0.8 \%$, respectively [23]. Each assay was performed according to the manufacturer's specification. Fasting plasma glucose concentrations were measured using the glucose oxidase technique. Plasma total cholesterol, HDL cholesterol and triglyceride levels were measured by enzymatic techniques using reagents from BoerhingerIngelheim (Mannheim, Germany). Fasting insulin concentrations were determined using an Abbott immunoassay on an Architect i2000 analyser [23]. Laboratory personnel undertaking the biochemical analyses were blinded to the sample origin. Insulin resistance was estimated using the homeostasis model assessment of insulin resistance (HOMA-IR), which was calculated as fasting insulin $x$ fasting glucose / 22.5 (glucose in mmol/L) [24].

\subsection{Pre-existing type 2 diabetes}

Of the 2745 men recruited, participants who reported having a history of diabetes at baseline ( $n=62)$ were excluded as were participants who had missing baseline fasting glucose measurements either due to lack of sample availability $(n=611)$ or who did not fast for at least 8 hours $(n=41)$. Also excluded were those who had a fasting baseline glucose concentration $\geq 7 \mathrm{mmol} / \mathrm{l}$, the World Health Organisation diagnostic criterion $(\mathrm{n}=180)$. No follow-up was available for 12 men and therefore analyses were performed on 1839 men without type 2 diabetes at baseline.

\subsection{Diabetes follow-up}

Between 1991 and 2010, participants were contacted bi-annually by letter and, if necessary, by telephone, to complete a clinical event questionnaire in order to obtain information on the incidence of new cases of diabetes. For the purposes of this study, incident diabetes was defined as follows: a) a positive response to the question "Since we last contacted you, have you been told by a doctor that you have diabetes”, and either b) self-reported use of oral hypoglycaemic drugs during follow-up or c) subsequent general practitioner (GP) 
confirmation of type 2 diabetes. Positive responses to a) and b) were subsequently validated by a questionnaire completed by the participant's GP. This questionnaire was also used to ascertain whether the participant had type 1 or type 2 diabetes, the date of onset, the type of treatment being administered (i.e. oral drugs, insulin or diet) and the location of treatment management (GP clinic or hospital). If an exact day and month of diagnosis was not provided, then the midpoint of the year of diagnosis was used. Participants with self-reported diabetes not validated by the GP or by antidiabetic medication were included in the analyses as being non-diabetic, but censored at the time of the annual contact preceding their selfreported diabetes $(n=17)$. The mean duration of follow-up (SD) was 14.7 (4.7) years. During the follow-up period, there were 408 deaths and these were confirmed by examination of the relevant death certificates. Participants who died were censored for type 2 diabetes at the date of last contact.

\subsection{Statistical analysis}

Data were summarised as mean and SD except where distributions were positively skewed, in which case the variables were logarithmically transformed and results presented as geometric mean and interquartile range (IQR). Chi-square tests were used to compare categorical data which included smoking status (never, ex or current), alcohol intake (none, $\leq 168 \mathrm{ml} / \mathrm{wk}$ or $>168 \mathrm{ml} / \mathrm{wk})$ and physical activity (<47.9, 47.9 - 84.99, 85.0 - 131.3, >131.3 MET hr/wk). Pearson correlation coefficients were used to examine associations between adipokines and diabetes risk factors. Cox proportional hazard regression models were used to assess the relative risk of type 2 diabetes according to baseline adipokine concentrations. Participants were divided into thirds according to the distribution of adiponectin and leptin concentrations, with the lowest third being used as the reference category. Potential confounding factors included in the analyses were established lifestyle risk factors, biological risk factors and more novel risk factors known to be associated with type 2 diabetes including 
HOMA-IR and CRP. The confounding factors included in the analyses have been previously highlighted in the literature as showing strong associations with risk of type 2 diabetes. Model 1 was adjusted for age; Model 2 was adjusted for age, BMI and WHR; Model 3 was adjusted as for Model 2 plus alcohol, smoking, socio-economic status and physical activity; Model 4 was adjusted as for Model 3 plus total cholesterol, HDL cholesterol, triglycerides, systolic blood pressure, drug treatment for hypertension and CRP; Model 5 was adjusted as for Model 4 plus HOMA-IR. Survival probabilities at 5, 10 and 15 y were estimated from Kaplan-Meier graphs (not shown). For all analyses, $\mathrm{p}<0.05$ was considered statistically significant. Statistical analyses were performed with SPSS v17.0 for Windows (SPSS Inc, Chicago, IL).

\section{Results}

During the follow-up period, there were 151 newly reported cases of diabetes. For 145 men, type 2 diabetes was ascertained by self-report questionnaire along with confirmation from their family doctor while in the remaining six men diabetes was ascertained by self-report questionnaire combined with self-reported use of hypoglycaemic drugs.

Table 1 describes the baseline demographic, anthropometric and metabolic characteristics of participants with and without type 2 diabetes at the end of the follow-up period. The mean (SD) BMI of participants was 26.1 (3.3) $\mathrm{kg} / \mathrm{m}^{2}$ and 261 (14\%) were obese (waist circumference $>102 \mathrm{~cm}$ or $\mathrm{BMI} \geq 30 \mathrm{~kg} / \mathrm{m}^{2}$ ). The men who developed type 2 diabetes during follow-up had a significantly higher BMI at baseline compared to men who did not $(\mathrm{p}<0.001)$. Other baseline measures of adiposity, including waist and hip circumference and WHR, were also higher in these men and a greater proportion were classified as obese at baseline, based on waist circumference $>102 \mathrm{~cm}$ or BMI $\geq 30 \mathrm{~kg} / \mathrm{m}^{2}$ (all $\mathrm{p}<0.001$ ). They also had significantly higher baseline systolic and diastolic blood pressure, triglycerides, CRP, 
glucose concentrations, insulin resistance (HOMA-IR) and leptin concentrations than those who did not develop diabetes during the follow-up period $(\mathrm{p}<0.001)$ and a greater proportion were on drug treatment for hypertension $(\mathrm{p}=0.002)$, had lower physical activity levels $(\mathrm{p}=0.001)$ and had a history of smoking $(\mathrm{p}=0.03)$. Conversely, baseline concentrations of adiponectin and HDL cholesterol were significantly lower in those who subsequently developed diabetes compared to those who didn’t develop diabetes. No significant differences were evident in baseline age, total cholesterol and alcohol intake between those who developed diabetes and those who did not. However, these factors were retained in the relevant regression models as they are well established risk factors for type 2 diabetes.

The cumulative rate for developing type 2 diabetes at 5, 10 and 15 y was $0.5 \%, 2.7 \%$ and 7.7\% respectively. The incidence rates and adjusted relative risks (RRs) of type 2 diabetes according to thirds of adiponectin and leptin distribution are presented in Table 2. Men in the highest category for adiponectin and in the lowest category for leptin had reduced risk of developing type 2 diabetes after adjusting for age (model 1). This association became slightly attenuated, but remained significant, after further adjustment for BMI and WHR (model 2) and lifestyle factors (model 3). Further adjustment for biological risk factors, including CRP (model 4), resulted in loss of significance for leptin. Model 4 remained statistically significant for adiponectin, but, when further adjusted for HOMA-IR, although men who were in the highest third for adiponectin had a $46 \%$ reduced risk of developing type 2 diabetes compared to those in the lowest third, this association was no longer significant (model 5). There were no significant interactions between the categories of leptin or adiponectin and type 2 diabetes. There was also no evidence of an interaction between adiponectin or leptin and HOMA on type 2 diabetes risk. 


\section{Discussion}

In this prospective, population-based study of non-diabetic middle-aged men, low concentrations of adiponectin and high concentrations of leptin were associated with a higher risk of developing type 2 diabetes independent of age, BMI, WHR and socioeconomic factors. However, after adjustment for biological risk factors, including lipids, blood pressure and CRP, the significant association between leptin and diabetes risk disappeared. Additional adjustment for HOMA-IR, an indirect marker of insulin resistance, also resulted in loss of significance for the association between adiponectin and type 2 diabetes risk.

Previous epidemiological evidence regarding the association between leptin and the onset of type 2 diabetes is somewhat conflicting. High levels of leptin have been shown to be independently associated with diabetes in some [8-11] but not all studies [7, 12-15, 18]. Of these studies, only two were UK population based studies [7, 10]. Welsh et al [10] reported a positive association between leptin and type 2 diabetes in men, but not women, after adjusting for confounding factors. In contrast, another UK based study by Wannamethee et al [7] showed no independent association between leptin and subsequent diabetes. Instead, they reported that obesity and insulin resistance explained most of the association between leptin and subsequent diabetes risk. Other studies also suggest that abdominal adiposity may modulate the association between leptin and type 2 diabetes [9, 12, 14, 15, 25].

The evidence regarding the association between adiponectin and type 2 diabetes is also conflicting. In contrast to the findings of the current study, a meta-analysis of 15 prospective studies by Li and colleagues [16] showed an inverse association between plasma adiponectin and risk of type 2 diabetes, however not all of the studies included in that meta-analysis adjusted for markers of insulin sensitivity. Consistent with our findings, a number of other prospective studies which did adjust for other biological factors, such as markers of insulin 
sensitivity found no independent association between low adiponectin levels and increased type 2 diabetes risk [11, 17, 18, 26]. The current study also found no evidence of an interaction between adiponectin and insulin resistance. Another recent study by Lilja et al [27] reported that high adiponectin levels were associated with decreased risk of type 2 diabetes in both insulin-sensitive and insulin-resistant individuals. In contrast, a study by Hivert et al [28] observed that adiponectin offered greater protection in insulin resistant men than in insulin sensitive men. The reason for the inconsistency in results across the studies is not clear. The attenuating effect of HOMA on the relationship between adiponectin and Type 2 diabetes, as observed in the current study, could also suggest that insulin resistance is acting as a mediator on the pathway between adiponectin concentrations and type 2 diabetes development.

The mechanism by which adiponectin affects glucose tolerance is not yet fully understood but it has been attributed to its insulin-sensitizing and anti-inflammatory properties $[4,5]$. A decrease in adiponectin is believed to precede the onset of insulin resistance [4], but this has not yet been proven and has also been questioned [28]. It remains unclear whether adiponectin has a causal effect on diabetes or is simply acting as a surrogate marker for some other metabolic risk factor(s). Unlike adiponectin, persistently high levels of leptin exert proinflammatory effects and are involved in upregulating other cytokines associated with insulin resistance and type 2 diabetes [29]. Recent evidence has highlighted that chronic inflammation may be an important contributory factor in the pathogenesis of type 2 diabetes [30-32] through its effects on insulin sensitivity and insulin secretion.

Strengths of the current study include the prospective design and the long follow-up period (14.7 \pm 4.7 y). The results presented are representative of a UK based population, for which there is relatively limited data available relating to the association between adipokines and 
onset of diabetes. Unlike a number of previous studies which were limited in their ability to adjust for important confounding factors, the current study included a wide range of biological and lifestyle covariates, particularly measures of adiposity and insulin resistance.

Limitations of the study include its observational design and the high number of deaths during follow-up which may have resulted in selection bias. During the follow-up period there were 408 deaths recorded (22\%). Another limitation is that the participants were all middle-aged to older men, therefore it is difficult to generalise the findings to women or younger age groups. It is also possible that some cases of diabetes were missed at baseline, as an oral glucose tolerance test was not carried out. Moreover, HbA1C which is a clinical indicator of blood glucose concentration and is commonly used for identifying people with diabetes was not measured. In addition, adiponectin and leptin were only measured at baseline and therefore we cannot rule out the possibility of change in these parameters over time. A further limitation, in common with all observational studies, is the possibility of residual confounding or failure to include other potential confounders.

\section{Conclusion}

In summary, after adjusting for potential confounding factors, neither high leptin nor low adiponectin concentrations were independent predictors of increased risk of type 2 diabetes among healthy middle-aged men. Indeed, the associations observed between leptin, adiponectin and incident type 2 diabetes were largely explained by biological factors and insulin resistance, respectively. This study challenges the findings from previous studies which observed statistically significant associations between adipokines and onset of type 2 diabetes and suggests that such findings may have been due to a failure to adequately adjust for confounding factors, such as insulin resistance. 


\section{Acknowledgments}

The authors wish to thank all the participants in the study for their time, interest, co-operation and contribution to research. This study was funded by a Department of Education and Learning Obesity grant. The PRIME study was originally funded by a Programme grant from Northern Ireland HSC Research and Development Fund. The funding organisation played no role in the design and conduct of the study; collection, management, analysis, and interpretation of the data; or in the preparation, review, or approval of the manuscript. The corresponding author had full access to all of the data in the study and takes responsibility for the integrity of the data and the accuracy of the data analysis. All of the authors contributed to the drafts, revisions and proof reading of the manuscript.

\section{Conflicts of interest: None}

\section{References}

[1] Diabetes UK (2013) Diabetes Prevalence 2013. Available from http://www.diabetes.org.uk/About_us/What-we-say/Statistics/Diabetes-prevalence-2013/. Last accessed 28 April 2015

[2] Antuna-Puente, Feve B, Fellahi S, Bastard JP. Adipokines: the missing link between insulin resistance and obesity. Diabetes Metab 2008;34:2-11

[3] Lago F, Gomez R, Gomez-Reino JJ, Dieguez C, Gualillo O. Adipokines as novel modulators of lipid metabolism. Trends Biochem Sci 2009;34:500-510

[4] Deng Y and Scherer PE. Adipokines as novel biomarkers and regulators of the metabolic syndrome. Annals NY Acad Sci 2010;1212:E1-E19 
[5] Sattar N. Biomarkers for diabetes prediction, pathogenesis or pharmacotherapy guidance? Past, present and future possibilities. Diabet Med 2012;29:5-13

[6] Thorand B, Zierer A, Baumert J, Meisinger C, Herder C, Koenig W. Associations between leptin and the leptin/adiponectin ratio and incident Type 2 diabetes in middle-aged men and women: results from the MONICA / KORA Augsburg study 19842002. Diabet Med. 2010;27(9):1004-11.

[7] Wannamethee SG, Lowe GDO, Rumley A, Cherry L, Whincup PH, Sattar N. Adipokines and risk of Type 2 diabetes in older men. Diabetes Care 2007;30:1200-05

[8] Soderberg S, Zimmet P, Tuomilehto J, Chitson P, Gareeboo H, Alberti KG, et al. Leptin predicts the development of diabetes in Mauritian men, but not women: a population-based study. Int J Obes 2007;31:1126-33

[9] McNeely MJ, Boyko EJ, Weigle DS, Shofer JB, Chessler SD, Leonnetti DL et al. Association between baseline plasma leptin levels and subsequent development of diabetes in Japanese Americans. Diabetes Care 1999;22:65-70

[10] Welsh P, Murray HM, Buckley BM, de Craen AJ, Ford I, Jukema JW, et al. Leptin predicts diabetes but not cardiovascular disease: results from a large prospective study in an elderly population. Diabetes Care 2009;32:308-10 
[11] Julia C, Czernichow S, Charnaux N, Ahluwalia N, Andreeva V, Touvier M, et al. Relationships between adipokines, biomarkers of endothelial function and inflammation and risk of type 2 diabetes. Diabetes Res Clin Pract 2014;105:231-38

[12] Sun Q, van Dam RM, Meigs JB, Franco OH, Mantzoros CS, Hu FB. Leptin and soluble leptin receptor levels in plasma and risk of Type 2 diabetes in U.S. women: A prospective study. Diabetes 2010;59:611-18

[13] Kanaya AM, Fyr C, Vittinghoff E, Harris TB, Park SW, Goodpaster BH, et al. Adipocytokines and incident diabetes mellitus in older adults: the independent effect of plasminogen activator inhibitor 1. Arch Intern Med 2006;166:350-56

[14] Bandaru P, Shankar A. Association between plasma leptin levels and diabetes mellitus. Metab Syndr Relat Disord 2011;9:19-23

[15] Ley S, Harris SB, Connelly PW, Mamakeesick M, Gittelsohn J, Hegele RA, et al. Adipokines and incident type 2 diabetes in an Aboriginal Canadian population. Diabetes Care 2008;31:1410-15

[16] Li S, Shin HJ, Ding EL, van Dam RM. Adiponectin levels and risk of type 2 diabetes: A systematic review and meta-analysis. JAMA 2009;302:179-88

[17] Hanley AJ, Wagenknecht LE, Norris JM, Bergman R, Anderson A, Chen YI, et al. Adiponectin and the incidence of type 2 diabetes in Hispanics and African Americans: the IRAS Family Study. Diabetes Care 2011;34:2231-36 
[18] Snijder MB, Heine RJ, Seidell JC, Bouter LM, Stehouwer CDA, Nijpels G, et al. Associations of adiponectin levels with incident impaired glucose metabolism and type 2 diabetes in older men and women: the Hoorn Study. Diabetes Care 2006;29:2498-503

[19] Yarnell JW. The PRIME study: classical risk factors do not explain the severalfold differences in risk of coronary heart disease between France and Northern Ireland. Q J Med 1998;91:667-76

[20] Wagner A, Simon C, Evans A, Ducimetiere P, Bongard V, Montaye M, et al. Physical activity patterns in 50-59 year men in France and Northern Ireland. Associations with socioeconomic status and health behaviour. Eur J Epidemiol 2003;18:321-29

[21] De Koning L, Gerstein HC, Bosch J, Diaz R, Mohan V, Dagenais G, et al. Anthropometric measures and glucose levels in a large multi-ethnic cohort of individuals at risk of developing type 2 diabetes. Diabetologia 2010;53:1322-30

[22] Qiao Q and Nyamdorj R. Is the association of type II diabetes with waist circumference or waist-to-hip ratio stronger than that with body mass index? Eur J Clin Nutr 2010;64:30-34

[23] Blankenberg S, Zeller T, Saarela O, Havulinna AS, Kee F, Tunstall-Pedoe H, et al. Contribution of 30 biomarkers to 10-year cardiovascular risk estimation in 2 population cohorts: the MONICA, risk, genetics, archiving, and monograph (MORGAM) biomarker project. Circulation 2010;121:2388-97 
[24] Matthews DR, Hosker JP, Rudenski AS, Naylor BA, Treacher DF, Turner RC. Homeostasis model assessment: insulin resistance and beta-cell function from fasting plasma glucose and insulin concentrations in man. Diabetologia 1985;28:412-19

[25] Schmidt MI, Duncan BB, Vigo A, Pankow JS, Couper D, Ballantyne CM, et al. Leptin and incident Type 2 diabetes: risk or protection? Diabetologia 2006;49:2086-96

[26] Koenig W, Khuseyinova N, Baumert J, Meisinger C, Lowel H. Serum concentrations of adiponectin and risk of type 2 diabetes mellitus and coronary heart disease in apparently healthy middle-aged men: results from the 18-year follow-up of a large cohort from southern Germany. J Am Coll Cardiol 2006;48: 1369-77

[27] Lilja M, Rolandsson O, Norberg M, Soderberg S. The impact of leptin and adiponectin on incident type 2 diabetes is modified by sex and insulin resistance. Metab Syndr Relat Disord 2012;10:143-51

[28] Hivert MF, Sullivan LM, Shrader P, Fox CS, Nathan DM, D’Agostino RB Sr, et al (2011) Insulin resistance influences the association of adiponectin levels with diabetes incidence in two population-based cohorts: the Cooperative Health Research in the Region of Augsburg (KORA) S4/F4 study and the Framingham Offspring Study. Diabetologia 2011;54:1019-24

[29] Otero M, Lago R, Lago F, Casanueva FF, Dieguez C, Gomez-Reino JJ, et al. Leptin, from fat to inflammation: old questions and new insights. FEBS Lett 2005;579:295-301 
[30] Donath MY, Shoelson SE. Type 2 diabetes as an inflammatory disease. Nat Rev Immunol 2011;11:98-107

[31] Donath MY, Schumann DM, Faulenbach M, Ellingsgaard H, Perren A, Ehses JA. Islet inflammation in type 2 diabetes: from metabolic stress to therapy. Diabetes Care 2008;31:S161-64

[32] Bongartz T, Kudva Y. Can treatment of chronic inflammatory diseases reduce the risk of diabetes mellitus? JAMA 2011;305:2573-74 
Table 1: Baseline characteristics of participants according to diabetes status at follow-up

\begin{tabular}{|c|c|c|c|}
\hline & \multicolumn{2}{|c|}{ Developed diabetes } & \multirow[b]{2}{*}{ p value } \\
\hline & No $(n=1688)$ & Yes $(\mathrm{n}=151)$ & \\
\hline Age (y) & $54.8(2.9)$ & $55.1(2.8)$ & 0.21 \\
\hline BMI $\left(\mathrm{kg} / \mathrm{m}^{2}\right)$ & $25.9(3.2)$ & $28.4(3.6)$ & $<0.001$ \\
\hline $\begin{array}{l}n(\%) \text { obese (i.e. waist }>102 \mathrm{~cm} \\
\left.\text { or } \mathrm{BMI} \geq 30 \mathrm{~kg} / \mathrm{m}^{2}\right)\end{array}$ & $215(12.7)$ & $46(30.5)$ & $<0.001$ \\
\hline Waist (cm) & $90.6(8.8)$ & $96.5(9.1)$ & $<0.001$ \\
\hline Hip (cm) & $96.4(6.4)$ & $100.0(7.8)$ & $<0.001$ \\
\hline Waist:hip ratio & $0.94(0.05)$ & $0.97(0.05)$ & $<0.001$ \\
\hline $\begin{array}{l}\text { Smoking status n (\%): } \\
\text { - Never } \\
\text { - Former } \\
\text { - Current }\end{array}$ & $\begin{array}{l}581(34.4) \\
585(34.7) \\
522(30.9)\end{array}$ & $\begin{array}{l}43(28.5) \\
69(45.7) \\
39(25.8)\end{array}$ & 0.03 \\
\hline $\begin{array}{l}\text { Alcohol intake n (\%): } \\
\text { - Teetotal } \\
\text { - } \leq 168 \mathrm{~g} / \mathrm{wk} \text { ( } \leq 21 \text { units) } \\
\text { - > 168g/wk }\end{array}$ & $\begin{array}{l}668(39.6) \\
475(28.1) \\
545(32.3)\end{array}$ & $\begin{array}{l}63(41.7) \\
43(28.5) \\
45(29.8)\end{array}$ & 0.81 \\
\hline $\begin{array}{l}\text { Total physical activity (MET } \\
\text { hr/wk) n (\%) } \\
-<47.9 \\
-47.9-84.99 \\
-85.0-131.3 \\
->131.3 \\
\text { - Unknown }\end{array}$ & $\begin{array}{l}359(21.3) \\
382(22.6) \\
374(22.2) \\
383(22.7) \\
190(11.2)\end{array}$ & $\begin{array}{l}46(30.5) \\
24(15.9) \\
30(19.9) \\
23(15.2) \\
28(18.5)\end{array}$ & 0.001 \\
\hline SBP (mmHg) & $132.1(20.2)$ & $139.9(22.2)$ & $<0.001$ \\
\hline DBP (mmHg) & $80.9(11.4)$ & $84.6(11.6)$ & $<0.001$ \\
\hline Hypertensive n (\%) & $586(34.7)$ & $80(53.0)$ & $<0.001$ \\
\hline $\begin{array}{l}\text { Currently on drug treatment } \\
\text { for hypertension } \mathrm{n}(\%)\end{array}$ & $142(8.4)$ & $24(16.6)$ & 0.002 \\
\hline Adiponectin $(\mu \mathrm{g} / \mathrm{ml})$ & $5.08(3.34,7.73)$ & $3.61(2.44,5.56)$ & $<0.001$ \\
\hline Leptin (ng/ml) & $4.16(2.27,6.84)$ & $7.19(4.54,11.87)$ & $<0.001$ \\
\hline CRP (mg/L) & $1.60(0.79,3.04)$ & $2.37(1.28,4.52)$ & $<0.001$ \\
\hline Fasting glucose (mmol/L) & $5.27(4.91,5.67)$ & $5.57(5.15,6.17)$ & $<0.001$ \\
\hline HOMA-IR & $1.30(0.92,1.86)$ & $2.17(1.58,3.06)$ & $<0.001$ \\
\hline Triglycerides (mmol/L) & $1.65(1.17,2.28)$ & $2.29(1.64,3.14)$ & $<0.001$ \\
\hline
\end{tabular}




\begin{tabular}{llcc}
\hline HDL cholesterol $(\mathrm{mmol} / \mathrm{L})$ & $1.20(0.32)$ & $1.03(0.26)$ & $<0.001$ \\
Total cholesterol (mmol/L) & $5.88(1.00)$ & $5.89(1.03)$ & 0.94 \\
\hline
\end{tabular}

Excludes participants who had diabetes at baseline

Continuous variables are presented as mean (SD) or geometric mean (IQR) for skewed variables

Categorical variables are presented as n (\%).

Differences between groups analysed using independent samples t-test for continuous variables and chi-square test for categorical variables

HOMA-IR, Homeostasis model assessment of insulin resistance 
Table 2: Relative risk of type 2 diabetes by thirds of adiponectin and leptin in healthy non-diabetic men

\begin{tabular}{|c|c|c|c|c|c|c|}
\hline \multirow[b]{2}{*}{ Categories } & \multirow{2}{*}{$\begin{array}{l}\text { Rate / } \\
1000 \\
\text { person } \\
\text { years } \\
\end{array}$} & \multicolumn{5}{|c|}{ Adjusted relative risk (95\% CI) } \\
\hline & & Model 1 & Model 2 & Model 3 & Model 4 & Model 5 \\
\hline \multicolumn{7}{|l|}{ Adiponectin ( $\mu \mathrm{g} / \mathrm{ml})$} \\
\hline$<3.77(\mathrm{n}=467)$ & 8.8 & 1.00 & 1.00 & 1.00 & 1.00 & 1.00 \\
\hline $3.77-6.66(n=467)$ & 5.6 & $0.62(0.41,0.93)$ & $0.67(0.44,1.00)$ & $0.64(0.42,0.97)$ & $0.71(0.47,1.09)$ & $0.92(0.60,1.43)$ \\
\hline$>6.66(\mathrm{n}=463)$ & 2.2 & $0.24(0.14,0.42)$ & $0.33(0.19,0.58)$ & $0.29(0.17,0.52)$ & $0.37(0.20,0.67)$ & $0.54(0.29,0.99)$ \\
\hline $\mathrm{p}$ for trend across thirds & & $<0.001$ & $<0.001$ & $<0.001$ & 0.001 & 0.07 \\
\hline \multicolumn{7}{|l|}{ Leptin (ng/ml) } \\
\hline$<2.93(\mathrm{n}=591)$ & 2.5 & 1.00 & 1.00 & 1.00 & 1.00 & 1.00 \\
\hline $2.93-6.00(n=601)$ & 3.9 & $1.61(0.95,2.74)$ & $1.07(0.62,1.85)$ & $1.00(0.58,1.74)$ & $0.88(0.50,1.53)$ & $0.74(0.43,1.29)$ \\
\hline$>6.00(n=595)$ & 10.2 & $4.27(2.67,6.83)$ & $1.93(1.13,3.29)$ & $1.75(1.02,3.01)$ & $1.43(0.77,2.34)$ & $0.91(0.51,1.60)$ \\
\hline p for trend across thirds & & $<0.001$ & 0.004 & 0.01 & 0.14 & 0.99 \\
\hline $\begin{array}{l}\text { Model 1: Adjusted for age } \\
\text { Model 2: Adjusted for age, B } \\
\text { Model 3: Adjusted for model } \\
\text { score), physical activity } \\
\text { Model 4: Adjusted for model } \\
\text { Model 5: Adjusted for model } \\
n=1397 \text { for adiponectin ; } n=\end{array}$ & $\begin{array}{l}\text { MI and wa } \\
2 \text { variables } \\
3 \text { variables } \\
4 \text { variable }\end{array}$ & $\begin{array}{l}\text { ist:hip ratio } \\
\text { + alcohol status, smol } \\
\text { + total cholesterol, H } \\
\text { + HOMA-IR } \\
\text { eptin }\end{array}$ & $\begin{array}{l}\text { zing status, measures o } \\
\text { DL cholesterol, triglyce }\end{array}$ & $\begin{array}{l}\text { ocioeconomic status (i } \\
\text { des, systolic BP, on dru }\end{array}$ & acludes material condi & $\begin{array}{l}\text { tions and deprivation } \\
\text { tension, CRP }\end{array}$ \\
\hline
\end{tabular}

